\title{
ASSESSMENT OF QUALITY OF OCCUPATIONAL HEALTH SERVICES IN EGYPT
}

\author{
By \\ Kamal AM., EL Okda EE. and Hakim S. \\ Community, Environmental and Occupational Health Department Ain Shams University
}

\begin{abstract}
:
Objectives: To measure degree of satisfaction of different customers as regard occupational health services in the form of preemployment, periodic medical examination and compensation committee. To find out risk factors responsible for dissatisfaction. Subjects and methods: The current research is a cross-sectional study at El-Nile health insurance hospital which serves factories of the East Delta region and el-Obour factories. The study was performed in 4 aspects: the first aspect includes all workers attending periodic medical examination clinic twice per week as external customers for one year, the second aspect includes: health care providers as internal customers and in the third phase of the study safety personnel in the studied industries were included. Interview questionnaire was used to find out different risk factors of dissatisfaction of the studied candidates. The $4^{\text {th }}$ aspect of the study includes Delphi questionnaire by mail to take consensus on the proposed plan for quality improvement of occupational health services. Results: more than $57 \%$ of the studied workers were satisfied by preemployment examination, while only $25.8 \%$ were satisfied by periodic medical examination, and more than $46 \%$ of the studied workers were satisfied by the occupational specialist. But zero \% of the studied cases were satisfied by the compensation committee and more than $77 \%$ of the studied cases were unsatisfied with this committee. Concerning the occupational committee about $13 \%$ of the studied workers were very unsatisfied with the occupational committee, and $2 \%$ were very unsatisfied by periodic medical examination. More than $48 \%$ of workers complain of, the unavailability of medications. More than $60 \%$ of them report that doctors consider this process as a routine procedure, while $55 \%$ were complaining of small number of doctors in comparison to the number of the workers. About $85 \%$ of the studied workers not satisfied with the results of laboratory data.
\end{abstract}

Conclusions: It is concluded that major causes of dissatisfaction with pre-employment 
examination where, low number of doctors, rapid examination, routine procedure, factory delay and non specific examination. While major causes of dissatisfaction with occupational health specialist and periodic medical examination were, long time, inaccurate investigations, no explanation of diagnosis, and no enough chairs for waiting. Key words: Periodic medical examination, workers satisfaction, Delphi questionnaire, pre-employment examination.

\section{Introduction}

The international organization for standardization (IOS) states that quality is best defined as those characteristics of a service that best satisfy stated or implied needs. This can also be applied to health care and occupational health services (OHSs). One of its implications is that the opinion of the consumer of health services is now valued more highly than before (ILO, 1985).Customer satisfaction is a person's feeling of pleasure or disappointment resulting from comparing a product/ service perceived performance or outcome in relation to his or her expectations. As this definition makes clear, satisfaction is a function of perceived performance and expectations. If the performance falls short of expectations, the customer is dissatisfied. If the performance matches the expectations, the customer is satisfied. If the performance exceeds the expectations, the customer is highly satisfied or delighted (John, 2008).

Occupational health services are those health care services primarily concerned with maintaining the health of people at work or those who were injured before or exposed to hazards at workplace (Finnish institute of occupational health, 2007).

Good quality of occupational health services is a crucial issue. To build effective acceptable occupational services there are different ways, from these essential ways is listening to the voice of customers through customer satisfaction surveys to know what satisfies or dissatisfies them and hence be able to plan the offered services with quality features that attract new customers and retain old ones (Jenkinson et al, 2002). In Egypt, the working population represents a large percentage of the total national population about 20 million individuals (CAPMAS, 2008). This large working population is the backbone for Egyptian economy. Their work and productivity are vital for improving the available resources and at the same time any problems affecting their health or production would be of negative impact on our future: there would be the cost of lost product, injury to workers and the 
cost of remedy or rehabilitation. The most valuable resource for most employers is their personnel. Maintaining the health and effective work performance of employee groups is enhanced by strong and well delivered occupational health care services. Employers needs in this area includes: access to urgent care services for on-plant medical problems, regulatory compliance assistance and medical specialists able to identify the effect of work exposures on employee health (Andrzejak et al, 2006).

The quality of occupational health services has to be high and under continuous monitoring and improvement. Research in that field is thus essential to obtain baseline data about causes of dissatisfaction with the quality of offered occupational health services and use these data for improvement and planning. However, unfortunately research in the field of occupational medicine is limited especially from developing countries which calls for urgent studies in that field to overcome the gap and enhance the quality of offered services.

\section{Objectives}

To measure degree of satisfaction of different customers as regard occupational health services in the form of preemployment, periodic medical examination, occupational specialist and compensation committees.

To find out risk factors responsible for dissatisfaction.

\section{Subjects and Methods}

Type of the study: The current research is an analytical cross-sectional study

Study site: El-Nile health insurance hospital which serves factories of the East Delta region and El-Obour factories, the study was carried out on four aspects:

\section{1- Aspect of workers as external customers of the offered occupational health services:}

Study population: All workers seeking occupational health services at the hospital on two days weekly (Mondays and Tuesdays) for one year and half starting from June 2006 to October 2007.

Study tool: Interviewing the worker using a pre-designed questionnaire after taking an oral consent from the worker to be included in the study and after explaining the objectives of this study to them. 
2- Aspect of health care providers of occupational health services at El-Nile hospital as internal customers. All health care providers were included using an interview questionnaire including their socio-demographic characteristics and causes of dissatisfaction if present with suggestions for improvement.

3- Aspect of industrial safety personnel who accompany the worker during his journey through the hospital. They stated their opinion using a pre-designed questionnaire. They were randomly selected and represented a total of 30 subjects.

4- Delphi technique was used to obtain consensus about items that should be included in the proposed plan for improvement.

\section{Ethical consideration:}

All participants in the study were informed by the objectives of the study, assured that the data were confidential and their personal data will never be revealed. An oral consent was obtained from them before asking them any question in the study.

Statistical methodology: Statistical program for social science (SPSS) version 15 was used for processing of the studied data. Description of quantitative variables as mean and SD. Qualitative variables were described as number and percentage. Pareto chart was used for detection of the vital few causes of the dissatisfaction. 


\section{Results}

Table (1): Distribution of workers according to their degree of satisfaction with the occupational health services:

\begin{tabular}{|l|c|c|c|c|c|c|c|c|}
\hline \multirow{2}{*}{$\begin{array}{l}\text { Satisfaction with } \\
\text { offered services: }\end{array}$} & \multicolumn{2}{|c|}{$\begin{array}{c}\text { Pre-employment } \\
\text { examination } \\
\mathrm{N}=630\end{array}$} & \multicolumn{2}{c|}{$\begin{array}{c}\text { Periodic medical } \\
\text { examination } \\
\mathrm{N}=620\end{array}$} & \multicolumn{2}{c|}{$\begin{array}{c}\text { Occupational } \\
\text { committee } \\
\mathrm{N}=37\end{array}$} & \multicolumn{2}{c|}{$\begin{array}{c}\text { Compensation } \\
\text { committee } \\
\mathrm{N}=9\end{array}$} \\
\cline { 2 - 11 } & No. & $\%$ & No. & $\%$ & No. & $\%$ & No. & $\%$ \\
\hline Very unsatisfied & 0 & 0 & 12 & 2 & 5 & 13.5 & 0 & 0 \\
\hline unsatisfied & 105 & 16.7 & 368 & 59.4 & 9 & 24.4 & 7 & 77.8 \\
\hline neutral & 31 & 5 & 30 & 4.8 & 8 & 21.6 & 2 & 22.2 \\
\hline satisfied & 360 & 57.1 & 160 & 25.8 & 11 & 29.7 & 0 & 0 \\
\hline Very satisfied & 134 & 21.2 & 50 & 8 & 4 & 10.8 & 0 & 0 \\
\hline
\end{tabular}




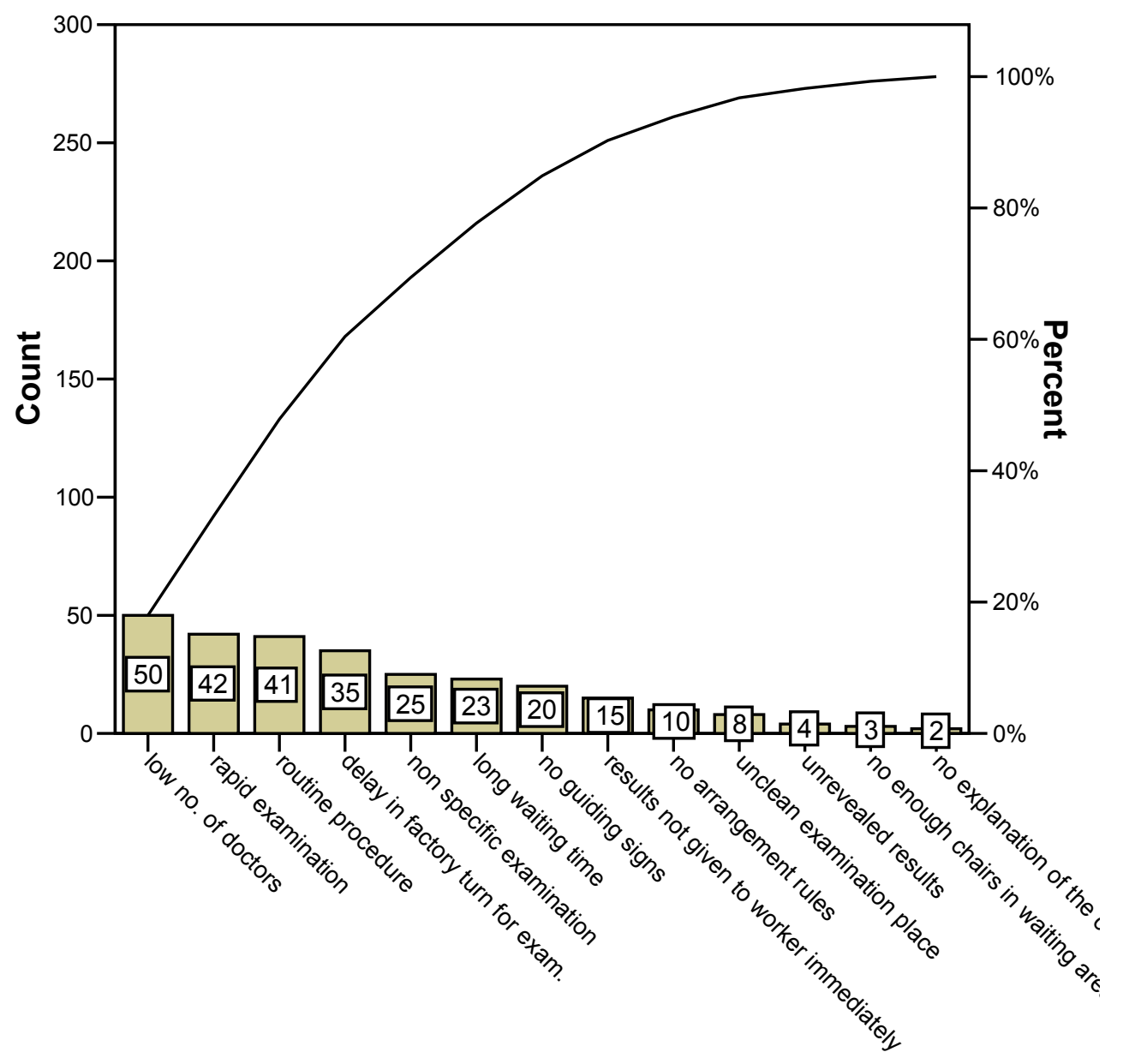

Figure (1): Pareto diagram revealing the causes of dissatisfaction with pre-employment examination 
Table (2): Causes of dissatisfaction with periodic medical examination services as reported by the workers:

\begin{tabular}{|l|c|c|c|c|}
\hline \multirow{2}{*}{$\begin{array}{c}\text { Causes of dissatisfaction } \\
\text { (total=380) }\end{array}$} & \multicolumn{2}{|c|}{ Yes } & \multicolumn{2}{c|}{ No } \\
\cline { 2 - 6 } & No. & $\%$ & No. & $\%$ \\
\hline 1- Interfering examination dates with work shifts. & 124 & 32.6 & 256 & 67.4 \\
\hline 2- Unprofessional physician. & 73 & 19.2 & 307 & 80.8 \\
\hline 3- Inattentive physician. & 90 & 23.7 & 290 & 76.3 \\
\hline 4- Rapid, non-specific examination. & 142 & 37.4 & 238 & 62.6 \\
\hline $\begin{array}{l}\text { 5- No explanation to what is happening during } \\
\text { examination. }\end{array}$ & 9 & 2.4 & 299 & 78.6 \\
\hline 6- Unrevealed results. & 98 & 25.8 & 282 & 74.2 \\
\hline 7- No offered medications. & 185 & 48.7 & 195 & 51.3 \\
\hline 8- A routine procedure. & 230 & 60.5 & 150 & 39.5 \\
\hline 9- Wide intervals between examinations. & 100 & 26.3 & 280 & 73.7 \\
\hline 10- Delayed investigation results. & 10 & 2.6 & 370 & 97.4 \\
\hline 11- Small number of physicians. & 210 & 55.3 & 170 & 44.7 \\
\hline 12- No private prepared place for examination. & 50 & 13.2 & 330 & 86.8 \\
\hline 13- Repeating investigation due to inaccurate results. & 80 & 21.1 & 300 & 78.9 \\
\hline
\end{tabular}


Table (3): Causes of dissatisfaction with occupational health committee services as reported by the workers:

\begin{tabular}{|l|c|c|c|c|}
\hline \multicolumn{2}{|c|}{$\begin{array}{c}\text { Causes of dissatisfaction } \\
\text { (total=14) }\end{array}$} & \multicolumn{2}{|c|}{ Yes } & \multicolumn{2}{c|}{ No } \\
\cline { 2 - 6 } & No. & $\%$ & No. & $\%$ \\
\hline 1- Long waiting time. & 8 & 57.1 & 6 & 42.9 \\
\hline 2- No enough chairs at the waiting area. & 10 & 71.4 & 4 & 28.6 \\
\hline $\begin{array}{l}\text { 3- Repeating the laboratory and radiology tests because } \\
\text { they were not accurate. }\end{array}$ & 12 & 85.7 & 2 & 14.3 \\
\hline 4- Unconvinced with the decision of the physician. & 14 & 100 & 0 & 0 \\
\hline
\end{tabular}

Table (4a): Distribution of health care providers according to their level of satisfaction with the health services they offer:

\begin{tabular}{|l|c|c|}
\hline Level of satisfaction & No. & $\%$ \\
\hline Unsatisfied & 12 & 54.5 \\
\hline satisfied & 10 & 45.5 \\
\hline
\end{tabular}


Table (4b): Causes of un-satisfaction as mentioned by the health care providers:

\begin{tabular}{|l|c|c|c|c|}
\hline \multirow{2}{*}{ Causes of un-satisfaction: (Total=12) } & \multicolumn{2}{|c|}{ Yes } & \multicolumn{2}{|c|}{ No } \\
\cline { 2 - 6 } & No. & $\%$ & No. & $\%$ \\
\hline 1- Shortage in the number of health care providers. & 9 & 75 & 3 & 25 \\
\hline 2- Low financial reward. & 11 & 91.7 & 1 & 8.3 \\
\hline 3- Sheet used does not fulfill needed information. & 2 & 16.7 & 10 & 83.3 \\
\hline 4- Instruments used in examination are not up dated. & 6 & 50 & 6 & 50 \\
\hline $\begin{array}{l}\text { 5- Slowness in managing any problems that arise during } \\
\text { work. }\end{array}$ & 4 & 33.3 & 8 & 66.7 \\
\hline 6- Examination place is not clean with weak illumination. & 1 & 8.3 & 11 & 91.7 \\
\hline 7- Quality of x-ray films is bad. & 5 & 41.7 & 7 & 58.3 \\
\hline 8- Patient record keeping system is bad. & 7 & 58.3 & 5 & 41.7 \\
\hline 9- Personal protective devices are not suitable for usage. & 3 & 25 & 9 & 75 \\
\hline 10- Malingering non cooperative workers. & 1 & 8.3 & 11 & 91.7 \\
\hline
\end{tabular}


Table (5): Causes of dissatisfaction with occupational health services examination as stated by industrial safety workers:

\begin{tabular}{|l|c|c|c|c|}
\hline \multirow{2}{*}{\begin{tabular}{|} 
Causes of dissatisfaction \\
(n=30)
\end{tabular}} & \multicolumn{2}{c|}{ Yes } & \multicolumn{2}{c|}{ No } \\
\cline { 2 - 5 } & No. & $\%$ & No. & $\%$ \\
\hline $\begin{array}{l}\text { 1- Number of physicians was less than number } \\
\text { of workers to be examined }\end{array}$ & 22 & 73.3 & 8 & 26.7 \\
\hline 2- Unclean Waiting places & 8 & 26.7 & 22 & 73.3 \\
\hline 3- Crowded place of examination & 15 & 50 & 15 & 50 \\
\hline 4- No guiding signs to places of examination. & 3 & 10 & 27 & 90 \\
\hline $\begin{array}{l}\text { 5- Dates reserved for examination are usually } \\
\text { after a long time }\end{array}$ & 20 & 66.7 & 10 & 33.3 \\
\hline $\begin{array}{l}\text { 6- Administrative staff treated the workers } \\
\text { badly. }\end{array}$ & 3 & 10 & 27 & 90 \\
\hline 7- No order to examination. & 2 & 6.7 & 28 & 93.3 \\
\hline 8- Bad patient-doctor relationship & 12 & 40 & 18 & 60 \\
\hline
\end{tabular}

\section{Results}

Table (1) shows that more than $57 \%$ of the studied workers were satisfied by preemployment examination, while only $25.8 \%$ were satisfied by periodic medical examination, about $2 \%$ were very unsatisfied by periodic medical examination. Zero percent of the studied cases were satisfied by the compensation committee and more than $77 \%$ of the studied cases were unsatisfied with this committee. Concerning the occupational committee about $13 \%$ of the studied workers were very unsatisfied with the occupational committee.

Table (2) shows that, more than $48 \%$ of the workers complained of: Unavailability of medications and more than $60 \%$ of them report that doctors consider this process as a routine procedure. More than $55 \%$ of the studied workers were complaining of small number of doctors.

Figure (1): Pareto diagram revealing the causes of dissatisfaction with pre- 
employment examination where the first five causes could be regarded as the vital few: low number of doctors, rapid examination, routine procedure, factory delay and non specific examination and the rest as the useful many

Table (3) this table shows that $100 \%$ of the studied workers were not convinced with the decision of the physician, while more than $85 \%$ of them were not trusting in the laboratory investigations and other investigations as usually they need to be repeated.

Table ( $4 \mathrm{a}$ and $4 \mathrm{~b})$ ) reveals that 12 health care providers out of 22 were not satisfied by occupational health services they offer. The major causes of dissatisfaction of health care providers were low financial reward $(91.7 \%)$ and limited number of the health care providers in relation to number of workers $(75 \%)$.

Table (5) reveals that major causes of dissatisfaction of safety workers as regard offered occupational health services were: low number of doctors (73.3\%) and inappropriate date for examination in relation to work schedule $(66.7 \%)$.

\section{Discussion:}

The present study was conducted on all stakeholders for occupational health services belonging to the authority of El Nile Hospital and related industries. About 630 workers were included to explore their degree of satisfaction as regard preemployment examination services. As shown in table (1) $21.2 \%$ of the studied workers were very satisfied by the preempolyment services. About 57\% of the studied workers were satisfied by the service. On the other hand $16.7 \%$ of the studied workers were unsatisfied by the preemployment services. Causes of poor satisfaction with the preemployment examination were arranged in Pareto chart (1). The vital few causes were shortage in the number of working physicians, the rapid rhythm of examination, the long time it takes for a factory workers turn to come in examination and the type of clinical examination which not satisfying worker complaint. These 5 causes were ranked in descending manner and represent about $38 \%$ out of 13 causes of poor satisfaction of preemployment examination. Working with these few 5 causes may participate in $80 \%$ improvement of preemployment services. These results partially agree with a study done by Hulshof et al, 1999 which includes different stakeholders for occupational health. The latter study concluded that poor satisfaction with preemployment examination was mainly 
due to lack of communication between health care providers and workers in addition to long waiting. Both causes represent $75 \%$ in cumulative percentage and considered vital few causes.

In the current study degree of satisfaction with preemployment examination is considered the best among all other studied sectors. In my own explanation this satisfaction may be due to desire of the employer to get the most suitable for worker for his job and more specific examination and investigations according to the type of the job.

As regards periodic medical examination, overall degree of dissatisfaction was $59.4 \%$. Several causes of dissatisfaction were stated in table (2) among which the workers' perception of this examination as a routine procedure (no real concern about their complaints and medical condition), the shortage in health care providers, no offered medications in case of disease diagnosis, the rapid non specific examination, the interfering dates of medical examination with their job schedules and the wide intervals between examination dates. These causes reflect the nature of periodic medical examination which occurs at regular intervals according to the type of exposure and involves all workers experiencing that exposure who usually represent a large number and the dates of clinical examination are appointed regardless their work shifts. These results totally agree with a study performed by ILO, 1985 in Geneva, in which degree of dissatisfaction of the studied workers regard periodic medical examination exceeds $61 \%$. In the latter study workers were considered this examination as a routine examination, no accuracy and huge number of them examined in the same time. The explanation of this issue in Egypt may be due to many factors the most important is the health insurance payment for the general practitioner who perform this examination in the industry about 10 piaster per worker. So if the doctor examine 1000 worker per month he will receive 100 pounds so the doctor should increase the number of examined workers irrespective to the quality or the outcome of examination. Another important issue was some industries fulfill the examination by collaboration with the doctor on papers only and not performed at all.

As regard satisfaction for occupational specialist, the overall degree of dissatisfaction was $22.9 \%$. The causes of dissatisfaction illustrated in the Pareto diagram no.2 and ranked as follow: 
long waiting time, having to repeat the investigations ordered by the physician due to inaccurate results, receiving no accurate explanation to a worker's case diagnosis and unprepared waiting areas (vital few causes for dissatisfaction). However, the higher percentage of workers reported their satisfaction with the offered services by the occupational specialist (table 1). This may be explained by the nature of this examination where cases are referred from the periodic medical examination to be examined by an occupational specialist and this may contribute to their satisfaction where they feel more concern is given to their condition. These results agree partially with a study by Venables and Allender, about occupational health provision in United Kingdom universities at 2007 which found that only $90 \%$ the studied workers were satisfied by the occupational consultant. The most important causes of dissatisfaction were due to staying for long time waiting the consultant. Regarding the occupational committee, about $24 \%$ of the studied workers were not satisfied with the committee. The major causes of dissatisfaction as shown from table (3) were: the workers' being unconvinced by the decision of the physician, the long waiting time and having to repeat the investigation due to non-accuracy of results.
However, the percentage of satisfied was higher than that of unsatisfied (table 1), this may be due to that examination takes place by a professor specialist in occupational medicine so workers feel more sure in diagnosis of their condition. These results disagree with a study by $\mathrm{Yi} \mathrm{T}$ et al for assessment of the provision of occupational health services in the construction industry in Hong Kong at 2002, workers satisfaction for occupational health services including occupational health committee and more than $50 \%$ of the studied workers were not satisfied by the decisions taken by the committee. The explanation of this difference may be due to difference in laws and regulations in different countries that control the occupational health services.

Several studies tried to find out the causes of patients' satisfaction or dissatisfaction with the offered health care services. From these studies discussing the factors affecting patient satisfaction, was one that found that the highest satisfaction was for discussing the psychological aspects of patients' problems and the lowest was for attentive listening to patient's complaints (Saeed et al, 2001). Another study indicated that the major determinants of patient satisfaction were physical comfort, emotional support and respect for 
patient preferences (Jenkinson et al, 2002). In another study, it was found that causes of dissatisfaction were mainly long waiting time, some patients reported they have never been asked for views on the quality of care provided, others said they did not find anyone in the staff to talk about their worries and fears, also others reported that, they were not provided enough information about their operative procedures beforehand (Imam et al, 2007). In the current study also many workers reporting that the doctor never asking them about their complaint before starting the examination. Some workers was complaining of examination is not specific to the exposure.

In the second section of results, the current study included the health care providers at El-Nile Hospital who represented the internal customers of the offered occupational health services at the hospital. Since it is important for a service to be successful to have both satisfied receivers and providers so it was important to study the other side of the service delivered. It was important to study the causes of their dissatisfaction in an attempt to identify these causes and then take action to correct them. Table $(4 a \& b)$ revealed the causes of dissatisfaction were: the small financial reward, shortage in the number of working staff, bad patient record keeping system and old not updated examination instruments. Some studies tried to find out the opinions of health care providers towards services they offer and the frequently stated causes of satisfaction or dissatisfaction. From these studies were: Shah et al, 2001 studied job satisfaction among health care professionals (physicians, nurses, medical laboratory technologists) in Kuwait they found that the nationality of the supervisor and in-service training showed a positive relationship with job satisfaction while the existence of unhealthy competition decreased job satisfaction. Another study revealed that professional opportunities, patient care and financial reward were the most frequently encountered domains with which physicians were dissatisfied. Exploring the relation between demographic and job characteristics with job satisfaction revealed that older, male, non-Saudi, specialists physicians had insignificantly higher mean score of job satisfaction than their counterparts (Al Juhani and Kishk, 2006).

\section{Conclusions}

This study showed that $59.4 \%$ and $16.7 \%$ of workers not satisfied with periodic medical examination and preemployment examination respectively. 
About $77 \%$ of the studied workers were not satisfied by compensation committee decisions. On the other hand major causes of dissatisfaction with preemployment medical examination were low number of doctors and rapid examination, while major causes for dissatisfaction for periodic medical examination were longer time for waiting of doctors and staff in addition to inaccurate investigations. Major causes of dissatisfaction of health care providers were low financial reward and low number in relation to workers, while safety workers reported that inappropriate number of doctors and in appropriate date of examination were the most important causes of their dissatisfaction.

\section{Recommendations}

It is recommended to revise financial rewarding of general practitioners and specialists working in occupational health services.

Continuous medical training for occupational health general practitioners guided by the Egyptian law of occupational diseases.

A quality improvement plan for occupational health clinics in industries and in health insurance hospital.

Orientation sessions for workers and other stakeholders about methods of calculation of compensation claims and disability evaluation.

\section{References:}

1- Al- Juhani AM and Kishk NA (2006). Job satisfaction among primary health care physicians and nurses in Al-Madinah Al-munawwara. J Egypt Public Health Assoc., 81(3-4):165-80.

2- Andrzejak R, Beck B, Urban J (2006). New image of occupational medicine--- current problems, future solutions, Med Pr., 2006; 57(2): 97-100.

3- Central Agency for Population Mobilization and Statistics (CAPMAS), 2008.

4- Finnish Institute of Occupational Health (2007). Occupational health services.

5- Imam SZ, Syed KS, Ali SA, Ali SU, Fatima K, Gill M, Hassan MO, Hashmi SH, Siddiqi MT, Khan HM and Jameel OF (2007). Patients satisfaction and opinions of their experiences during admission in a tertiary care hospital in Pakistan - a cross-sectional study. BMC Health Serv Res, 7:161.

6- International Labour Organization (1985). R171 Occupational Health Services Recommendation, Geneva, Switzerland: ILO.

7- ISO 9000 International Standards for quality management, second edition. Geneva (2000): ISO Central Secretarist.

8- Jenkinson C, Coulter A, Bruster S, Richards and N, Chandola T. (2002). Patients experiences and satisfaction with health care (2002): Results of a questionnaire study of specific aspects of care. Qual Saf Health Care,11(4): 335-9.

9- John F. Reh. (2008): Customer satisfaction survey. Occupational medical journal (Lond) 60:140-155.

10- Hulshof CTJ, Verbeek JHAM, van Dijk FJH, van der Weide WE, and Braam ITJ (1999). Evaluation research in occupational health services: general principles (Scandinavian journal of occupational health). 56:361-377.

11- Nair K.G. (2004): Customer satisfaction in hos- 
pitals. Health Care Management Indian journal of community medicine 30:130-141.

12-Saeed AA, Mohammed BA, Maqzoub ME and Al-Doqhaither AH (2001). Satisfaction and correlates of patients' satisfaction with physicians services in primary health care centers. Saudi Med J. Mar; 22(3):262-7.

13-Shah M.A., Al- Enezi N., Chowdhury R.I., and Shah N.M (2001): Correlates of job satisfaction among health care professionals in Kuwait. Med Princ Pract, vol. 10, no.3, 156-162.

14-Venables KM and Allender SA (2007). Occupational health provision in United Kingdom universities. Occup Med (Lond) 57:162-168.

15-Yi T-SI, Cheng FFK, Tse LA, and Wong TW (2002). Assessing the provision of occupational health services in the construction industry in Hong Kong. Occup Med (Lond) 52:375-382. 